\title{
GAS GANGRENE.
}

\author{
By RONALD W. RAVEN, F.R.C.S.
}

(Surgeon to Out-Patients, French Hospital, London; Assistant Surgeon, Royal Cancer Hospital (Free); Assistant Surgeon, Gordon Hospital; Consulting Surgeon, The Eversfield. Hospital, St. Leonards-on-Sea.)

Judgment is difficult when the knowledge of Hippocrates regarding Gas Gangrene is assessed. Albeit he describes the case of a man who developed pain, tenderness and redness in. the great toe with skin changes resembling small black blebs. There was evidently a marked degree of absorption of toxin from the gangrenous area for he had fever, nausea and vomiting and later he went completely " out of his head" and died two days after the onset of his illness. This important disease subsequently failed to attract the attention of those early shrewd observers in medicine until Fabricus de Hilden declared his belief "that the principal cause of this terrible ill is some venonous humor which Nature has driven into these people." In I745 Quesnay contributed a paper to medical literature on "Gangrene of putrid dissolution of the humeral mass" and called attention to three outstanding features, namely the subcutaneous emphysema, the erysipelatous colour of the skin and the rapidity of death. During the Napoleonic wars undoubted cases of gas gangrene were observed and treated, for Larrey described the rapid progress of traumatic gangrene with final dissolution under ten hours. The association of gas gangrene and fractures is spoken of in the writings of Boyer (I8I4) and Velpeau (I829). During the Crimean War cases of gas gangrene were encountered and have been recorded in the writings of Pirogoff and Salleron. It is interesting to note that during the American Civil War, Keen did not see a single example of the condition. Cases were met with during the Franco-Prussian War and the condition was described by Wyatt as occurring during the siege of Paris. During the Great War, I9I4-I9I8, considerable interest was necessarily displayed in the disease and the literature on the subject was enriched by the Medical Research Committee's publication on the "Anaerobic Infections of Wounds and the Bacteriological and Serological Problems arising therefrom." In America, also, excellent observations have been recorded in the Surgeon-General's report (U.S.A.).

\section{Bacteriological Considerations.}

The organism most commonly the cause of gas gangrene is the Clostridium welchii (syn. B.ærogenes capsulatus, B.perfringens, B.phlegmonis emphysematosæ). Another organism less commonly found is Clostridium œdematis maligni (syn. Vibrion septique) and yet another encountered is Bacillus œdematiens (syn. B.bellonensis, Clostridium novyi). Organisms rarely seen in association with gas gangrene are Clostridium hystolyticum, Bacillus enteritidis sporogenes, Bacillus proteins and Bacillus fallax. For all practical purposes, however, the first three organisms enumerated are the most important and amongst these the incidence of Clostridium welchii is much higher than the rest.

One of the least strict amongst the anaerobic group of organisms, Clostridium welchii is a gram-positive bacillus and spore-forming. It possesses a capsule, causes foamy fermentation of litmus milk and grows easiest in an alkaline medium. Large numbers of the organism flourish in the soil of a flat country, hence cultures from the battlefields of France were Ioo per cent. positive and cultures from war wounds sustained there were $8 \mathrm{I}$ per cent. positive. Other situations in which the 
organism may be found are normal intact skin and the intestinal tract. It has been cultured from the mouths of newly-born children, normal salivary glands, the pancreas and the vagina. Positive cultures have been obtained from chronic ulcers of the leg, the blood in typhoid fever and puerperal sepsis.

This varied incidence of Clostridium welchii is important, as the finding of the organism per se is without meaning and the diagnosis of gas gangrene based on the finding of this bacillus may be erroneous. During the Great War a series of 890 cases were investigated by means of wound culture and 53 per cent. contained anaerobic bacilli; of this number as much as 67 . per cent. showed no evidence of gas gangrene.

\section{Pathological Considerations.}

The tissue which appears to be most vulnerable in gas gangrene is the muscles although other tissues such as the subcutaneous fat may also be affected in a lesser degree. These affected tissues contain a large amount of carbon dioxide gas bubbles which are derived from the glycogen of muscle. The tissues become discoloured, soft and waxy, then necrotic and fluid, until finally gas filled pulp is produced. The overlying skin is swollen, pale and cold. The most striking feature of the lesion in the muscles is the absence of any inflammatory reaction. The muscle fibres are quiescent and there is an absence of wandering cells. Leucocytosis occurs in the subcutaneous and connective tissues, the leucocytes being of the polymorphonuclear variety. There is thrombosis of veins and capillaries but this is not invariable. In advanced lesions hæmorrhage and hæmolysis occur.

The anaerobic organisms are disseminated by three routes:-

(a) Direct extension in areolar and connective tissues.

(b) Extension along the lymphatic vessels.

(c) Invasion of the blood-stream.

The first mode of spread appears to be the most important, as infection passes from the wound through the tissues of the limb to involve the trunk. Lymphatic permeation occurs in a manner reminiscent of the spread of cancer cells. The regional lymph nodes may show degenerative changes. It appears that visceral lesions in gas gangrene are due to hæmatogenous dissemination.

The changes which can be demonstrated throughout the body are due to the action of circulating toxins or the circulating organisms.

(a). Changes ascribed to the action of circulating toxins.

(i) The Blood-thrombosis is commonly seen in the region of the primary wound and in smaller vessels throughout the body. Hæmolysis is also present in varying degrees and occurs early in the infection and the spleen often contains a large quantity of hæmosiderin.

(ii) The Spleen-the changes consist of œdema, thrombosis in the capillary vessels and pigmentation.

(iii) The Liver-there is cloudy swelling and occasionally fatty degeneration.

(iv) The Kidney-the cells undergo advanced cloudy swelling and often disintegrate. The changes, are constant and severe and the convoluted tubules are the chief sufferers. 
(b). Changes ascribed to the presence of the organisms.

(i) The Liver-the organisms which reach the liver by the blood-stream can be seen lying in the sinusoids. Colonies of organisms are formed and adjacent liver cells in a wide zone around perish, the changes being those of coagulation necrosis. In the late stages gas develops, compressing adjacent liver cells.

(ii) The Kidney-the changes are similar to those occurring in the liver.

(iii) - The Spleen-the lesions are of the usual type and are not uncommon.

(iv) Lymph nodes-infection of these structures is very common and necrotic changes are produced with lack of any reaction.

\section{Clinical Aspects of the Disease.}

From the clinical standpoint several types of the disease may be differentiated.

1. Localized infection in the wound.

2. Spreading infection in the wound.

3. Infection of a single muscle.

4. Infection of groups of muscles.

5. Infection of a segment of limb.

6. The fulminating type.

The symptomatology varies with the type of disease which is present. During the first phases pain is an outstanding symptom and this may be due to increase of tension in the wound. With the spread of infection pain increases and numbness is experienced in the limbs. The constitutional symptoms now become manifest and the patient is ill with fever, increased pulse rate, vomiting and cyanosis. Clarity of the mind persists to the end in spite of the increasing distress occasioned by exacerbation in the constitutional symptoms. Before final dissolution the extremities become blue and cold, the fever abates and icterus may be seen.

The physical signs vary with the type of disease. Thus, during the early phase there is a foul-smelling discharge containing gas bubbles. With progress of the infection the wound area becomes swollen and the overlying skin is blanched. Crepitation may be detected around the wound. Changes in the skin then become more marked with the development of a dusky hue giving place to purple mottling and finally assuming a greenish yellow colour. Large irregular bullæ containing blood-stained serous fluid are sometimes seen. It is important to remember that the gangrene may be advanced in underlying muscles without any marked change in the overlying skin. In the fulminating type of the disease in which the resistance of the patient is poor and the infecting organism is very virulent there is increased severity of the symptomatology.

\section{Factors influencing the Development of Gas Gangrene.}

\section{THE CONDITION OF THE PATIENT.}

As in all infections the development of gas gangrene is influenced by the resistance afforded by the patient. It was observed that the disease was more prevalent amongst patients whose powers of resistance were lowered by such factors as exposure to physical and mental adverse influences, fatigue, traumatic shock and hæmorrhage. 
THE NATURE OF THE TRAUMA.

During the Great War it was observed that irregular fragments of high explosive shells produced widespread devitalization and destruction of tissues and such wounds frequently became infected with anaerobic bacilli. The risk of infection is increased in these cases owing to the frequency of the missile carrying pieces of clothing and portions of soil into the tissues.

THE BLOOD SUPPLY OF THE INJURED TISSUES.

Diminution of the blood supply to the wounded area is an important predisposing factor in the development of gas gangrene. The blood supply may be interfered with on account of the general anæmia produced through loss of blood; the application of a tourniquet proximal to the wound may arrest blood flow; thrombosis of blood vessels in the neighbourhood of the wound.

\section{THE VARIETY OF WOUND.}

There are two varieties of wounds which are very liable to develop gas gangrene-wounds with imperfect drainage and wounds with extensive devitalization and death of tissue with extravasation of blood. Muscle tissue is much more susceptible to anaerobic infection than areolar tissue. The larger muscles with coarse fibres are more liable to infection, thus gas gangrene is much commoner in the gluteal muscles than in wounds of the skull and face. Serous membranes appear to possess considerable powers of resistance to this infection and in serous cavities the progress of the disease is slower and limited in extent.

\section{The Diagnosis of Gas Gangrene.}

It was formerly thought that tissue crepitation was the first sign of suspicion in gas gangrene. The diagnosis, however, must be reached before crepitation is present otherwise the early hours when treatment could be instituted will be lost and the mortality rate will reach a high figure. Further, the diagnosis must be reached in the absence of positive bacteriological evidence and the result of culture must not be awaited. Gas gangrene must be suspected in a wound contaminated with soil, fæces or dirty clothing and especially woollen clothing, when there is a sudden exacerbation of pain, rise in pulse rate out of proportion with the degree of fever, œdema of the soft tissues and discolouration of the skin. The smell of gas gangrene is that of a mouse and the characteristic odour is an important dirgnostic point. Radiological examination of the wounded area may reveal buibbles of gas in the tissues and crepitation may be elicited. Rhinehart has called attention to the value of $\mathrm{X}$-ray examination in the diagnosis of gas gangrene before important signs are clinically manifest. In suspected cases X-ray examination should be carried out at four-hourly intervals and any increase in the number of gas bubbles is noted. It is said that the X-ray diagnosis is many hours ahead of the clinical diagnosis. If the infecting organism is the Clostridium oedematis maligni no crepitation will be felt and no gas bubbles will be found on X-ray examination. There are two conditions which must be distinguished from gas gangrene-(a) hæmorrhage from a wound in a large blood vessel into the tissues; (b) odema following trauma of the tissues. In the former case the limb is swollen and firm, blood clot may be escaping from the wound, no gas bubbles are demonstrable on radiological examination, pain is less severe and constitutional symptoms are less marked. In the second case there is marked pain on palpation, herniation of the underlying tissues through the wound and absence of constitutional symptoms. 


\section{The Complications of Gas Gangrene.}

I. Gas Gangrene Septicamia. Anaerobic organisms may invade the blood stream causing septicæmia. In these cases the temperature is swinging in character, the general appearance is fairly good but there is progressive wasting. Subsequently pyogenic organisms enter the blood stream and when this occurs the patient soon succumbs.

2. Gas Gangrene Pyamia. This complication is fortunately rare and generally complicates anaerobic infection of a compound fracture. Secondary foci of gas gangrene develop in various parts of the body and especially where the tissues have been slightly damaged. The prognosis in these cases is grave.

\section{Gas Gangrene in Compound Fractures.}

Gas gangrene is not uncommonly seen in association with compound fractures and if suspected the injured limb should be immobilised in an open splint to facilitate easy and adequate inspection of the wound. If this complication is present, treatment is directed against it rather than the fracture, for its spread must be controlled as soon as possible. Surgical operations involve excision of damaged tissues and adjacent tissues should be exposed to the air by multiple longitudinal incisions. Carrell-Dakin irrigation of the wound may be instituted. If there is the slightest evidence of spread of the infection the affected limb must be amputated well above the infected area.

\section{Anaerobic Infections in Amputation Stumps.}

A careful investigation was carried out in the Hospital for Joint Diseases, New York into the causes, prevention and treatment of anaerobic infection in amputation stumps. It was found that vascular disease of the extremities in diabetes or arteriosclerosis is an important etiological factor. As a result of this investigation it was advised that in cases of gangrene, the gangrenous area should be cultured and if B.Welchii is present a prophylactic injection of anti-gas gangrene serum should be given. The gangrenous area of the limb should be carefully covered before the patient is sent to the operation theatre and the area is not exposed during the operation. A culture should be made of a portion of muscle at the site of amputation at the time of operation. When amputating through the thigh in the presence of a gangrenous area below, the flaps may be left open on account of potentially infected muscle planes and lymph spaces. In cases with gross trauma and infection of the leg it is often safer to perform a disarticulation at the knee joint as no muscular planes and relatively few fascial planes are opened. When the patient has recovered from this procedure a secondary amputation may be performed.

\section{The Treatment of Gas Gangrene.}

\section{Prophylactic treatment.}

It is of fundamental importance to recognise that mangled muscular tissue whose blood supply is interfered with is the ideal medium for the growth of anaerobic organisms. Other predisposing factors are retention of extravasated blood, wound secretions and foreign bodies. Extensive fractures and comminution of long bones favour the development of gas gangrene. Treatment must be directed to avoid these predisposing factors. 


\section{Surgical treatment.}

Surgical measures instituted in the treatment of gas gangrene will vary with the general condition of the patient and the extent of the gangrene.

(a) Local infection in a wound.

Complete excision of the wound must be performed with the removal of injured and infected tissues with any foreign material. If vital structures such as bone, blood vessels and nerves are involved in the, infection and they cannot be removed they must be carefully cleansed. Hæmorrhage must be controlled by ligature and not by packing the wound, for this further impairs the blood supply to the wound. Carrell-Dakin irrigation of the wound is carried out.

(b) Infection of muscular tissues.

The treatment depends on the general condition of the patient.

(i) The general condition is satisfactory. The affected tissues are carefully explored and the condition of the muscles is observed. It should be noted whether the muscle contracts, possesses the normal colour and bleeds when incised. All muscular tissues showing departure from normal regarding these three points must be excised. A complete muscle from origin to insertion may be excised and it may be necessary to sacrifice a group of muscles.

(ii) The general condition is unsatisfactory. If the general condition is poor it is likely that an associated fracture is present. In these cases amputation should be performed. The site of amputation will be dictated by the extent of the infection: It must be determined whether the muscles are normal at the site of the proposed amputation. When the tissues of the leg are infected disarticulation at the knee joint is recommended as. the_operative shock is lessened. It is necessary to remove the heads of the gastrocnemius muscles from the femur when performing this operation.

(c) Infection of a segment of the limb.

This variety will demand amputation of the limb. The site of amputation is dictated by the extent of the infection and amputation must be performed through normal tissues. Disarticulation at the knee joint is preferable to amputation through the thigh.

\section{(d) Fulminating infection.}

In these cases there is extensive and rapid spread of gangrene and immediate amputation is the only possible hope for the patient. It may even be necessary to amputate through tissues which are already infected and in these cases the skin flaps are left open and continuous irrigation by the Carrell-Dakin technique is instituted. If infected tissues are present above the site of amputation multiple incisions are made.

\section{The general treatment of the patient.}

(a) General nursing care of the patient is extremely important. Absolute rest, both mental and physical must be assured for the patient. All unnecessary movements for the patient must be avoided and all noise should be eliminated.

(b) The vicious circle of traumatic shock must be broken at the earliest possible moment lest the changes in the body become irreversible.

(c) The treatment of acidosis. Since acidosis is always a feature of these cases, alkaline therapy must be instituted. Alkali may be given by mouth but if 
the patient has marked vomiting 4 per cent. sodium bicarbonate solution can be given by the intravenous route.

\section{(d) Serum therapy.}

(i) As a prophylactic measure-Statistics built up from series of wounded men in the Great War indicate that serum therapy is a useful prophylactic measure.

(ii) As a therapeutic measure-It appears from cases published in the literature that serum therapy is of value in gas gangrene Eliason, Erb and Gilbert state that the mortality without serum varies from 30 to 83 per cent. Weinberg reported a series of 60 cases treated with serum with a mortality of 6.7 per cent. and Sacquépée I9I cases with a mortality of I3 per cent. Newell advocates the early intravenous administration of ro,000 to 30,000 units of polyvalent antitoxin repeated every six to eight hours.

\section{(e) Sulfanilamide therapy.}

It seemed reasonable to elucidate the action of sulfanilamide in cases of gas gangrene and the first cases were reported by Bohlman who considers that it is a valuable adjunct in treatment when combined with surgical measures. He states that sulfanilamide probably has a specific effect on gas bacilli, but the results in part may be due to checking symbiotic growth of streptococci.

4. Other methods employed in the local treatment of the wound.

I. Oxidation of the tissues. This may be effected by injecting oxygen into the tissues through the wound or into the surrounding tissues in an attempt to localise the infection. Oxidizing agents such as solutions of hydrogen peroxide or potassium permanganate have their advocates.

2. X-ray therapy. In America series of cases of gas gangrene have been treated by this form of therapy and results have been reported by Kelly, J. F., and Dowell, D. A. The technique employed resulted in delivering Ioo roentgens per treatment over each area. The treatment is given morning and evening over a minimum period of at least three days, the voltage employed being sufficient to insure penetration of the involved tissue. Thus 90 to Ioo kilovolts with I $\mathrm{mm}$. filter are used on an extremity and from I30 to I6o kilovolts with increased filtration on the trunk. The number of patients treated is small and it is difficult to dogmatise regarding the value of this form of therapy. It is necessary also, when endeavouring to assess the value of treatment, to group patients together into classes according to the severity of the disease and one definite method of treatment must be instituted in comparable groups. As far as I am aware this has not yet been done in the assessment of the value of X-ray therapy in cases of gas gangrene. As in all forms of therapy for lethal disease which give the patient a ray of hope further elucidation of the effects of X-ray therapy should be carried out.

3. Diathermic puncture. Recently Afonso published a paper on the treatment of Gas Gangrene in which he advocates the employment of extensive cauterisation for cases where the affected area is so large that excision is contraindicated on account of the poor general constitutional condition of the patient. Neighbouring healthy tissues are cauterised with a sharp-pointed cautery, encircling the gangrenous area with a line of superficial ignipunctures $I \mathrm{~cm}$. apart, $3 \mathrm{~cm}$. outside the necrotic area. The area of necrosis is incised in several situations and 
the cautery is inserted into each incision in order to cauterise the necrotic tissues in an endeavour to transform the necrotic tissues into a mass of combustion products making the life of anaerobic bacilli impossible. Afonso states that a gangrenous wound may be transformed by his technique into a granulating wound.

\section{CONCLUSION.}

Of all the complications of a wound none is more serious than the onset of gas gangrene. The disease always springs into prominence in time of war and therefore the present is an opportune moment for its review. In this paper certain historical data are given; the bacteriological and pathological aspects of the disease are described; the clinical features are presented and the various methods of treatment and their indications are discussed.

REFERENCES.

AFONSO, E. da C. Treatment of Gas Gangrene. Lancet, (1940) April 6. 644

BOHLMAN, H. R., Gas Gangrene Treated with Sulfanilamide, J.A.M.A., (1937), $109,254$.

BOLAND, F. K., Gas Gangrene in Compound Fractures, Ann. Surg., (1929), 90, 603.

BOYER, Des Maladies Chirurgicales, 1814.

ELIASON, E. L., ERB, W. H., and GILBERT, P. D., The Clostridium Welchii and Associated Organisms,

Surg. Gynæc. and Obst. (1937), 64, 1005.

HIPPOCRATES, Cuevres Completes d'Hippocrates. Traduction de Littre, (1840), Livre 1, 705.

KELLY, J. F., and DOWELL, D. A., Present Status of $X$-rays as an Aid in Treatment of Gas Gangrene.

J.A.M.A., (1936), 107, 1114

MILLAR, W. M., Gas Gangrene in Civil Life, Surg. Gynæc. and Obst. (1932), 54, 232.

NEWELL, E. D., Gas Gangrene, Ann. Surg. (1939), 110, 100.

PIROGOFF, Grundzuge allgem. Kriegschirurgie, Leipzig, (1864), 867

SALLERON, Arch de med. mil. (1858) 21, 300.

VELPEAU, Lecones orales de clin. Chirurg. (1841), 2. 